\title{
Fiscal Decentralization and High-Polluting Industry Development: City-Level Evidence from Chinese Panel Data
}

\author{
Lanrui Wang ${ }^{1}$ and Ping Lei ${ }^{1 *}$ \\ 1. School of Humanities and Economic Management of China University of \\ Geosciences (Beijing), Beijing, China \\ *. Corresponding Author: Ping Lei \\ leipingleiping@hotmail.com
}

\begin{abstract}
"Chinese-style separation of powers" not only brings miracle of peonomic development, but also exacerbate environmental pollution. This paper studiesthe effect of fiscal decentralization with the different pollution levels industry which the local government chosen to develop. A dynamic study based on the panel data of 69 major cities from 2001 to 2011. The results show that the fiscat inome decentralization may reduce the pollution level of regional industrial structure, but the sample statistical results is not significant in the eastern region; while fiscal expenditure decentralization could significantly improve the pollution level of regional industrid structure, which is an important index to investigate the continuousty rtsing industngl structure pollution level of sampling cities
\end{abstract}

Keywords: Fiscal decentralization Local government; Industrial structure; Pollution

\section{Introduction}

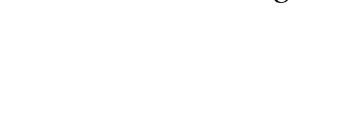

In recent years, China has made remarkable achievements. However, because China's economic growth has been achieved at the expense of supernormal resource consumption and serious eco-environmental degradation, constraints of environmental resources on China's economic development have become increasingly obvious. For instance, there is a significant positive correlation between the actual GDP and the amount of sulfur dioxide emission which is the major pollutants in china before 2005, as shown in Figure 1. Along with the economic grovth, industrial sulfur dioxide emission is also gradually rising. Cai Fang, Du Yang, etal (2008) pointed out that the current extensive mode of economic development caused environmental problems to China, and the government act under the Chinese decentralization system was the root cause of this extensive development mode. Existing studies on the relationship between fiscal decentralization and environmental pollutionare mainly focused on investigating fiscal decentralization and environmental regulations of local governments. However, environmental regulations should not be simplyequated with the environmental quality. Quite few studies discuss environmental effects of fiscal decentralization, while most studies remain at the provincial level (Ma Yuetal., 2013). ${ }^{1}$

Environmental pollution is mainly caused by the development of the secondary industry. Environmental pollution in a region relates to the size of its secondary industry, but has more bearing on the industrial segmentation structure of the secondary industry. Different industrial structures would bring different regional resource and environmental pressures $(\mathrm{Qu}$ Xiao'e, 2012). In final analysis, regional environmental problems are triggered by improper regional industrial structures. The core of fiscal decentralization influence on regional environment lies in the impact on the regional industrial structure.

Ping Lei is the corresponding author. 
As far as the author knows, the existing literature rarely focuses on the impact of fiscal decentralization on regional industrial structure. Therefore, details of the influence chain "fiscal decentralization - local government behavior - industrial change-environmental impact" are unknown. This paper is to figure out whether fiscal decentralization would produce influence on the regional industrial environment pollution structure and how the influence is produced.

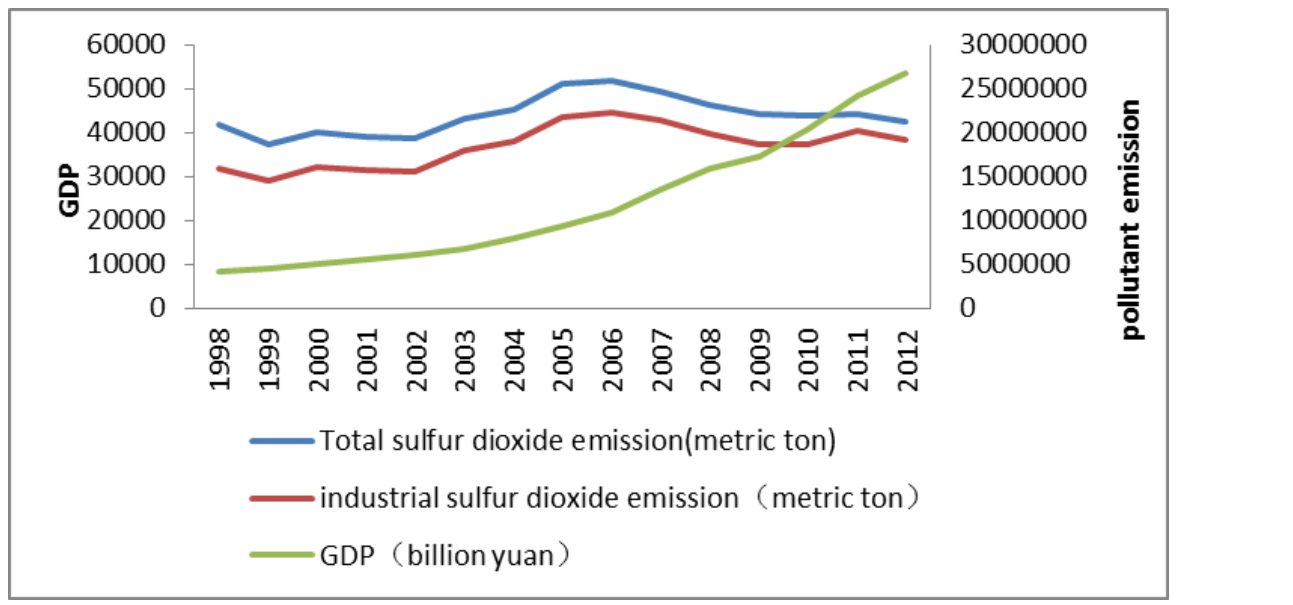

Figure 1. Economic Growth and Sulfur Dioxide Emission Levels of China

Data sources: China Statistical Yearbồ (1999-2013 )

This paper falls into four parts. The finst part introduces the fiscal decentralization in China. The second part describes the research design and data source. In the third part, empirical research is made. In the last part, conclusions of this research are drawn.

\section{Fiscal Decentralization in China}

According to modern theories of fiseal decentralization, because local governments enjoy information advantages, they can better identify the preference of local residents. Therefore, the center government's transfer of fiscal revenue and expenditure power to local governments can help to improve the economic efficiency and speed up local economic development (Oales, 1972).

In 1994, a new fiscal system - the tax-sharing system - was introduced to replace the old discretion-based system of revenue-sharing (the fiscal contracting system) in china. In the tax-sharing system all taxes are divided among the central government and local governments. The increasing proportion of central government fiscal revenue has brought the continuing financial pressures to local government. As can be seen from the Figure 2, the central government received more than $50 \%$ of the fiscal revenue, and undertaked abou $30 \%$ of the fiscal expenditure after the reform. At the same time, local governments bean the most of the public service. From the trend of Figure 2,the local government's vertical fiscal imbalance has become increasingly serious, the issue of fiscal deficit highlighted. As a result, the local governments have to work hard to raise taxes to fill the fiscal deficit. And one of the ways to increase the financial revenue is to promote the development of local economy rapidly.

The goal of fiscal decentralization is to elicit a local government's initiative. Although there is still a debate (Lin \& Liu, 2000; Zhang \& Zou, 1998), many authors argue that China's three decades of growth can be partly explained by its fiscal federalism (e.g., Blanchard \& Shleifer, 2001;Maskin, Qian, \& Xu, 2000;Montinola, Qian, \& Weingast, 1995; Qian \& Roland, 1998; Qian \& Xu, 1993). 
Fiscal decentralization plays an important role in the sustained economic growth in china, but the incentive distortion caused by the fiscal decentralization has also increased the environmental pollution. Blanchard and Shleifer (2001) highlight that under the tight control of the communist party, the central government in China has maintained a strong position to both reward and punish local administrations. To evaluate and promote the local officials, the central government may use the growth rates of the local economy, argued by Blanchard and Shleifer (2001) and Li and Zhou (2005), or revenue collection highlighted in Shih, Adolph, and Liu (2012). Therefore, it is more rational for the local officials to spend all investments on promoting growth, rather than spend them on controlling pollution. By so doing, their chances of promotion would be maximized.

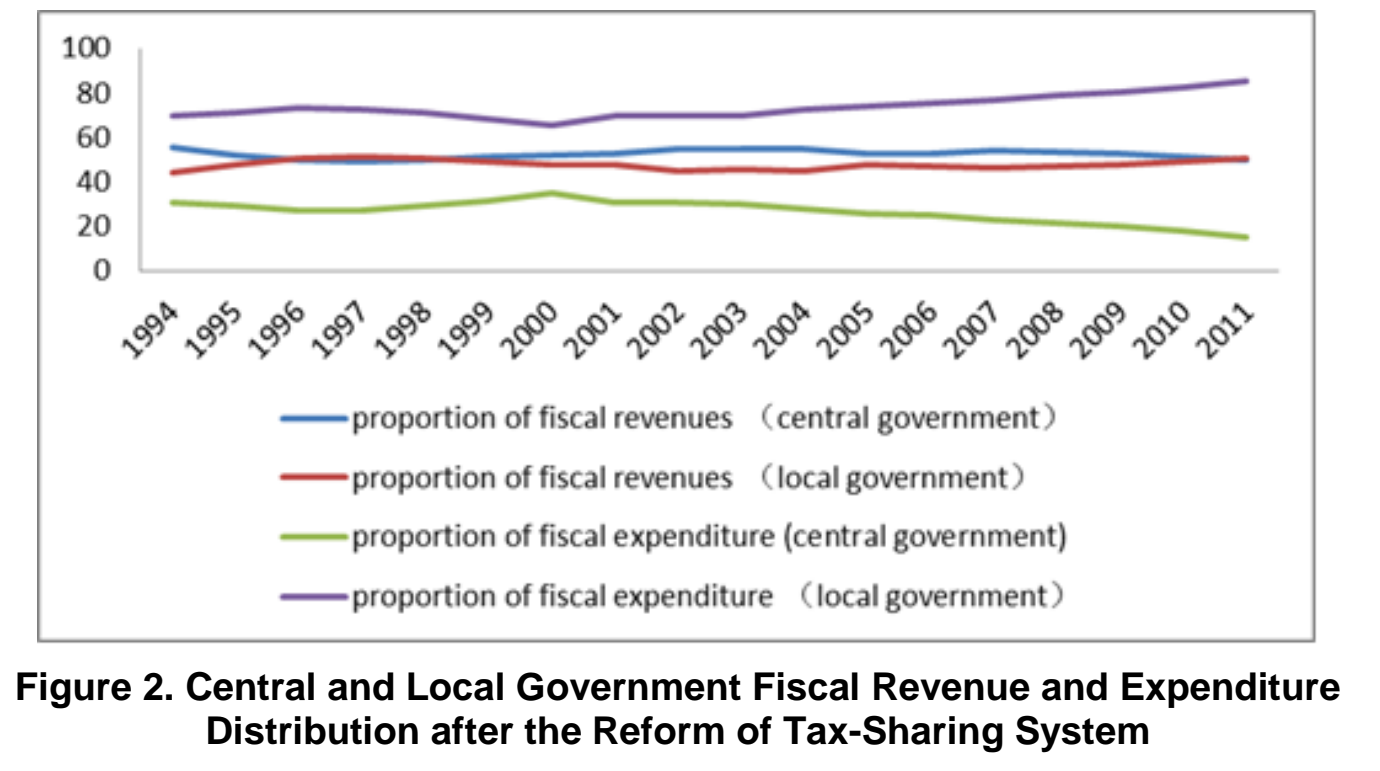

Data sources: Finance Vearbook of China (1995-2012).

Fiscal decentralizat on involves tho aspects: allocation of financial authority and office authority, which have different influence on government acts. Following the measurement index system of Oates (1985), income decentralization and expenditure decentralization can be use as measurementindexes of fiscal decentralization. Income decentralization is an index measuring fiscal decentralization according to fiscal income relations between governments, while expenditure decentralization is an index which measures fiscal decentralization aecording to fiscal expenditure relations between governments. The degree of rule-based fiscal decentralization still has substantial variations cross provinces, due to the gradual approach to reform in China. As shown in Figure 3, there is a big difference between income and expenditure decentralization in China and they have no corresponding relationship in the same region. So that it is necessary to discuss the different effects of them in the local government behavior. 


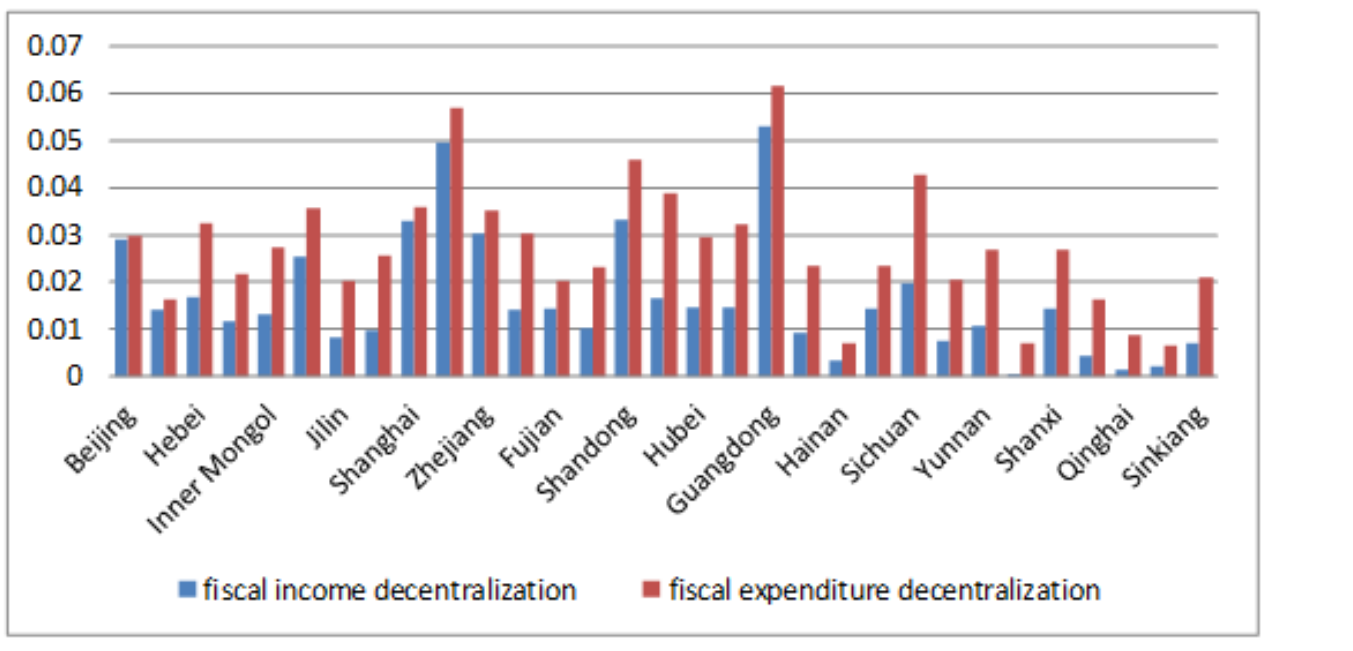

Figure 3. Degree of Fiscal Decentralization in the Provinces of China in 2011

Data sources: Finance Yearbook of China(2012), China Statistical Yearbook(2012).

\section{Data Source and Variable Descriptive Statistics}

\subsection{Data Source and Processing}

112 key Chinese cities were included into statistics of "China Statistic Yearbook on Environment". In view of the accessibility of regtonal 2-digit industrial data, relevant data of 69 key cities was collected in this research ${ }^{2}$.

The industrial structure pollution level was measured based on the 2-digit industrial structure and comprehensive envronmental pollution evaluation and energy consumption evaluation of various indispries. In order to improve the comparability of research results, this research used the caleulation method of Sun Weizeng, et al, (2014). The industrial structure pollution level can be caleulated through Equation (1).

$$
\mathrm{IND}_{\mathrm{it}}=\frac{\text { Pol }_{\mathrm{it}}}{\operatorname{Prod} \mathrm{d}_{\mathrm{it}}}=\frac{\Sigma_{\mathrm{N}}^{\mathrm{j}} \mathrm{Pol}_{\mathrm{ijt}} * \operatorname{Prod}_{\mathrm{ijt}}}{\sum_{\mathrm{j}}^{\mathrm{j}} \operatorname{Prod}_{\mathrm{it}}}
$$

Where IND is the industrial structure pollution level of key cities; i refers to city; $t$ is the year; Prod is the 2-digit industrial index. In an output-based perspective, the total industrial outpuralue was used to measure the industrial structure of each key city. Data was collected from annual statistical yearbooks of different provinces and cities. China changed the industrial classification system in 2011. In this paper, the industrial structure, which vas released by statistical yearbooks, was adjusted according to the 2002 national economic industrial classification system. By learning from the comprehensive evaluation index of the industrial environment pollution, which was put forward and used by $\mathrm{Qu}$ Xiao e (2014), this paper chose Pol as a comprehensive evaluation index for environmental pollution of second-digit manufacturing sectors. This index reflects pollution of six types of pollutants, such as the sulfur dioxide emissions, dust emissions,

\footnotetext{
${ }^{2} 69$ key Chinese cities include Anshan, Baotou, Baoding, Changzhou, Changchun, Changsha, Chengdu, Dalian, Daqing, Foshan, Fuzhou, Guangzhou, Guilin, Guiyang, Harbin, Haikou, Handan, Hangzhou, Hefei, Hohhot, Huzhou, Jilin, Jinan, Jining, Jiaxing, Jiamusi, Jingzhou, Kunming, Lanzhou, Lianyungang, Luoyang, Mianyang, Nanchang, Nanjing, Nanning, Nantong, Ningbo, Panzhihua, Qiqihar, Qingdao, Rizhao, Sanmenxia, Shantou, Shaoxing, Shenzhen, Shenyang, Shijiazhuang, Suzhou, Taizhou , Tai'an, Taiyuan, Tangshan, Weifang, Wenzhou, Urumqi, Wuxi, Wuhan, Xi'an, Xining, Xianyang, Xuzhou, Yinchuan, Zhanjiang, Zhenjiang, Zhengzhou, Zhongshan, Zhuhai and Zunyi.
} 
dust emissions, carbon dioxide emissions and solid waste, so it has good comprehensiveness and representativeness. According to the evaluation results, the industrial structure of second-digit manufacturing is divided into three kinds : heavy pollution industry, moderate pollution industry and light pollution industry as shown in Table 1.

Traditional fiscal decentralization indexes are varied. In their study of fiscal decentralization issues in China, Shen Kunrong and Fu Wenlin (2005) pointed out that fiscal decentralization indexes covering extra-budgetary fiscal expenditures were usually hard to pass test. In this paper, income decentralization which can represent the office authority and expenditure which can represent the financial authority were chosen to measure fiscal decentralization of key cities. Proportions of key cities' budgetary incomes in the budgetary income of a province were used to measure income decentralization, while proportions of key cities' budgetary expenditures in the budgetary expenditure of a province were used to measure expenditure decentralization. To ensure the ressearch precision, this research did not average data.

On the basis of preliminary research results, this research chose the leve of economic development (per capita GDP within a region), population density, research and development density (the proportion of the research and devêtopment expenditure in GDP), the manufacturing degree (the proportion of the secondary industry output in GDP of a region), foreign investment dependence (the proportion of foreign direct investment in GDP of a region) and other indexes as control variables.

\section{Table 1. Comprehensive Evaluation Resuits of Second-Digit Manufacturing Environment Pollution}

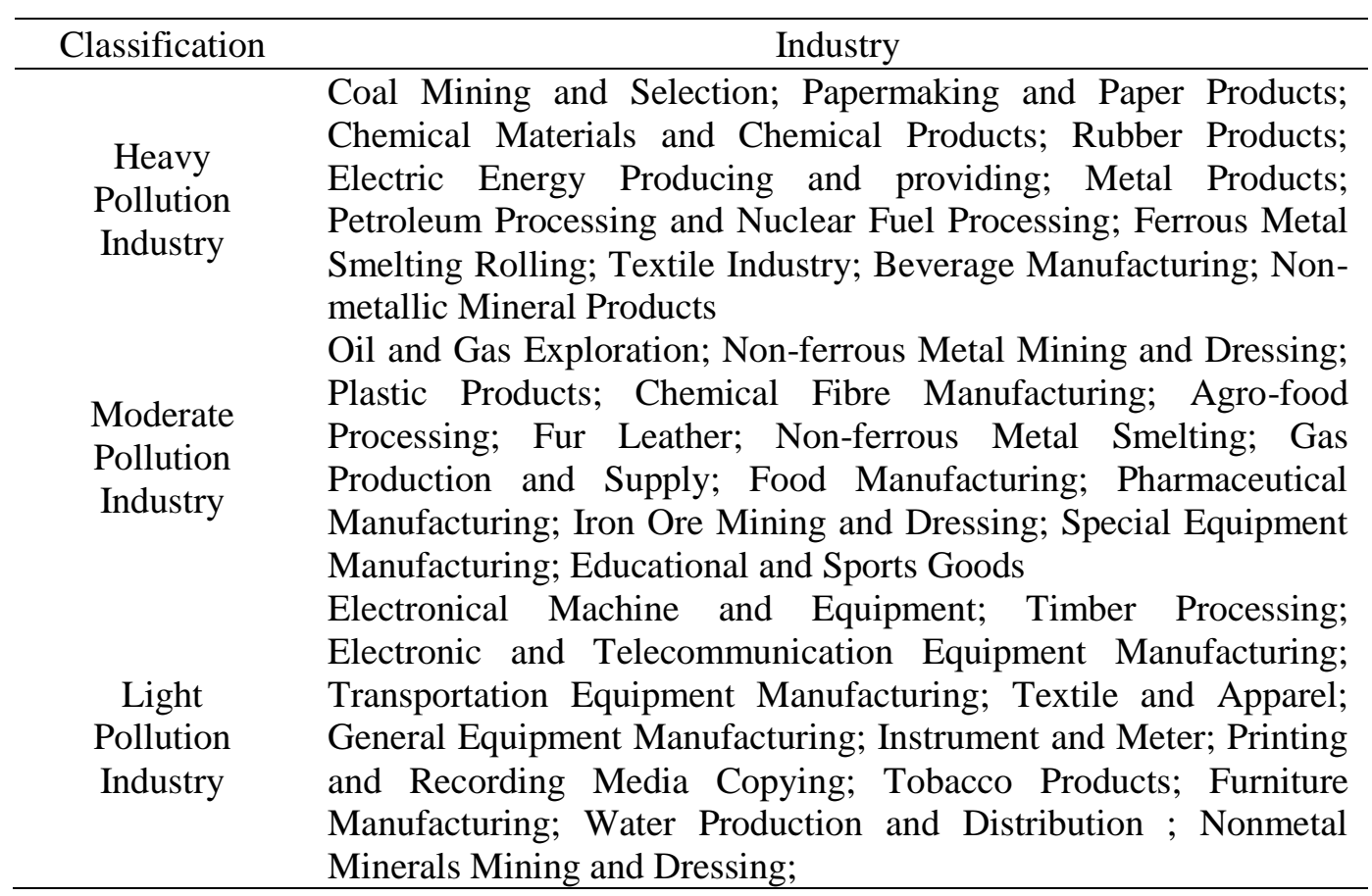

Above-mentioned data about the fiscal incomes and expenditures, GDP, population density, foreign direct investment and other indexes was collected from statistic yearbooks of various provinces and cities as well as the "China City Statistical Yearbook". Missing data was supplemented through the Chinese Economic and Social Development Statistical Database of CNKI. The foreign direct investment amount was converted into RMB according to the RMB-US dollar exchange rate; the regional GDP and total industrial output were converted into the 2001 level respectively according to the consumer price index and the product cost price; the per capita GDP was deflated to the 
2001 level, in consideration of the inflation rate. To reduce possible heteroscedasticity, this research took the natural logarithm of per capita GDP and population density to improve the regression quality.

Descriptive statistics of processed variables were shown in Table 2.

\subsection{Descriptive Statistics of Variables}

Table 2. Descriptive Statistics of Variables

\begin{tabular}{|c|c|c|c|c|c|c|}
\hline Variables & Full name & $\begin{array}{l}\text { Sample } \\
\text { size }\end{array}$ & $\begin{array}{l}\text { Mean } \\
\text { value }\end{array}$ & $\begin{array}{c}\text { Standard } \\
\text { deviation }\end{array}$ & $\begin{array}{l}\text { Minimum } \\
\text { value }\end{array}$ & $\begin{array}{l}\text { Maximum } \\
\text { value }\end{array}$ \\
\hline Indpol & Industry pollution & 809 & 0.391 & 0.0609 & 0.148 & 0.593 \\
\hline Deexp & $\begin{array}{l}\text { Decentralization of } \\
\text { expenditure }\end{array}$ & 853 & 0.138 & 0.107 & 0.00648 & 0.503 \\
\hline Deinc & $\begin{array}{l}\text { Decentralization of } \\
\text { income }\end{array}$ & 853 & 0.101 & 0.107 & $0 \cap 0$ & \\
\hline Pgdp & Per capita GDP & 852 & 10.25 & 1.163 & & 9.30 \\
\hline Popden & Population density & 853 & 6.173 & & & 8.299 \\
\hline $\mathrm{Rd}$ & Research density & 852 & & & & 0.0357 \\
\hline Manuf & $\begin{array}{l}\text { Manufacturing } \\
\text { degree }\end{array}$ & 852 & & & & 88.69 \\
\hline Fdidep & $\begin{array}{l}\text { Foreign direct } \\
\text { investment } \\
\text { dependence }\end{array}$ & & & & 0 & 0.208 \\
\hline
\end{tabular}

To avoid the multi-collinearity, correlation tests were made. Test results showed that the correlation coefficient of income decentralization and expenditure decentralization was 0.53 , while correlation coefficients of other variables were less than 0.30 . This indicates that this research had no problem of multi-collinearity. Corresponding testing details were omitted in this paper for saving space, but available for checking.

\section{Empirical Research}

\subsection{Research Design}

Due to the continuity of the regional industrial structure, the industrial structure of the current period is bound to be affected by the industrial structure of the past period. A dynamic panel nodel was developed as shown in Equation (2).

$$
\text { Indpol }_{\text {it }}=\alpha_{0}+\beta * \text { Decen }_{\text {it }}+\gamma * \mathrm{CV}_{\mathrm{it}}+\delta * \operatorname{Indpol}_{\mathrm{i}, \mathrm{t}-1}+\epsilon_{\mathrm{it}}
$$

Where, Indpol is the industrial structure pollution level within a region; $i$ is the sample size; nis the year; Decen is fiscal decentralization, CV is control variables. Because esidual serial correlation inevitably exists in the Equation (2), it is unsuitable to make fixed effect panel regression. In the panel model with residual serial correlations, the system GMM estimation method has better application. Moreover, to eliminate heteroscedasticity of samples, two-stage estimates were used. Arellano and Bond (1991) believed that the two-stage estimates had non-robust defects. However, simulation results of Windmeijer (2005) showed that bias-corrected robust standard errors could help to get better statistical inference. Learning from findings of Windmeijer (2005), this research chose the two-staged, bias-corrected and robust estimation equation (2), and used sargan statistical results to test excessive identification of instrumental variables. Owing to difference, the dynamic panel model allows first-order serial correlations between residual errors, but does not allow the existence of high-order (including second-order) serial 
correlation. Therefore, a test was made of the second-order serial correlations in the regression model in Table 3.

\subsection{Empirical Results}

Panel data of 69 key Chinese cities from 2001 to 2011 was analyzed to get regression results about the relationship between fiscal decentralization and the regional industrial pollution level. Model 1, 2 and 3 are regression models that take income decentralization as an independent variable, while Model 4, 5 and 6 investigates the relationship between the regional industrial structure pollution level and expenditure decentralization as an independent variable.

\section{Table 3. Table Empirical research of the Relationship between Fiscal Decentralization and Regional Industrial Structure Pollution}

\begin{tabular}{|c|c|c|c|c|c|c|}
\hline Variables & $\begin{array}{c}\text { (1) } \\
\text { National }\end{array}$ & $\begin{array}{c}(2) \\
\text { Eastern }\end{array}$ & $\begin{array}{c}\text { (3) } \\
\text { Non-eastern }\end{array}$ & $\begin{array}{c}\text { (4) } \\
\text { National }\end{array}$ & $\begin{array}{c}(5) \\
\text { Eastern }\end{array}$ & Jon-easte \\
\hline Indpolt-1 & $-0.2568 * * *$ & $-0.5870^{*}$ & & & & 85 \\
\hline & $(-39.63)$ & $(-56.10)$ & & & & $(-16.87)$ \\
\hline Deinc & $\begin{array}{c}-0.1433 * * * \\
(-9.88)\end{array}$ & $\begin{array}{c}0.0196 \\
(0.51)\end{array}$ & & & & \\
\hline deexp & & & & & $\begin{array}{c}* \\
(11.90)\end{array}$ & $\begin{array}{c}0.0150 * * * \\
(3.34)\end{array}$ \\
\hline Pgdp & $0.0134 * * *$ & & & $0.0132 * * *$ & $\begin{array}{c}0.0773 * * \\
*\end{array}$ & $0.0051^{* *}$ \\
\hline & (10.11) & & & (11.37) & (30.37) & (2.13) \\
\hline Po & & & & $\stackrel{-}{0.0053 * * *}$ & $0.0188^{* *}$ & -0.0030 \\
\hline & & & (1.52) & $(-3.66)$ & $(-5.33)$ & $(-0.67)$ \\
\hline $\mathrm{Rc}$ & & & $3.1047 * * *$ & $1.8906 * * *$ & $\begin{array}{c}5.0603 \\
* *\end{array}$ & $2.4828 * * *$ \\
\hline \multirow{5}{*}{ Manuft } & & $2646)$ & (6.68) & (25.79) & (18.40) & (6.74) \\
\hline & & $0.0009 * *$ & $0.0114 * * *$ & $0.0087 * * *$ & $\begin{array}{c}0.0016^{* * *} \\
*\end{array}$ & $0.0116^{* * *}$ \\
\hline & & (2.40) & (22.41) & (40.34) & $(4.25)$ & (19.24) \\
\hline & * & $-0.1545^{* * *}$ & $0.3112 * *$ & $\stackrel{-}{0.0922 * * *}$ & $\begin{array}{c}- \\
0.1290 * * \\
*\end{array}$ & $0.2903 * * *$ \\
\hline & $(-5.23)$ & (5.21) & (2.53) & $(-6.95)$ & (3.30) & (7.97) \\
\hline \multirow[t]{2}{*}{ Constant } & 0.0148 & $-0.1359 * * *$ & -0.0648 & $\stackrel{-}{0.0378 * * *}$ & $\begin{array}{c}- \\
0.2488 * * \\
*\end{array}$ & -0.0499 \\
\hline & (1.27) & $(-3.71)$ & $(-0.72)$ & $(-4.14)$ & $(-7.38)$ & $(-0.92)$ \\
\hline $\mathrm{AR}(1)$ & $-5.75 * * *$ & $-4.97 * * *$ & $-4.41 * * *$ & $-5.73 * * *$ & $-4.97 * * *$ & $-4.52 * * *$ \\
\hline $\mathrm{AR}(2)$ & -1.32 & -1.13 & -1.05 & -1.04 & -0.81 & -1.06 \\
\hline Sargan test & 71.82 & 36.89 & 34.46 & 71.92 & 36.88 & 34.39 \\
\hline $\mathrm{P}$ & 0.00 & 0.00 & 0.00 & 0.00 & 0.00 & 0.00 \\
\hline Sample size & 721 & 383 & 338 & 721 & 383 & 338. \\
\hline
\end{tabular}


Notes: (1) What are in the brackets are $\mathrm{z}$ statistics; (2) *, ** and *** represent statistical significance at the level 10\%, 5\% and 1\%, respectively; (3) The robust method is used to estimate standard errors.

Firstly, according to statistical results in the $1^{\text {st }}$ and $3^{\text {rd }}$ column (data of Model 1 and 3) of Table 3, it can be seen that income decentralization and the regional industrial structure pollution have a negative correlation. However, statistical results shown in the $2^{\text {nd }}$ column (data of Model 2) fail to pass the significance test, which indicates that income decentralization may lower the regional industrial structure pollution level. However, eastern samples do not show statistical significance. This is inconsistent with the previous research finding that improvement of income or expenditure decentralization can aggravate environmental pollution. This research got different results, perhaps for two reasons. On the other hand, income decentralization reflects the relationship of fiscal income power allocation between local governments and upper-level governments. Higher income decentralization indicates that local governments have greater rights and more freedom to use their local fiscal incomes. Income decentralization determines local governments' responsibility for regional governance. Therefore, higher income decentralization indicates that local governments should assume greater responsibility of party and government administration and pay more attention to coordinated development of economic and environmental society. Therefore, an jncrease in fiscal decentralization may lower the regional industrial structure pollution level. On the other hand, samples of this research are key cities in China. Compared with other regions and cities, these key cities play a more important role in economic society. Environmental pollution within a region greatly affects the social image and attraction of this Cegion, so governments of key cities tend to have more motivations to control further aggravation of environmental pollution in respective regions or cities. In this wa mome decentralization may be inversely proportional to the industrial structure pollution level.

Secondly, according to statisticatresults in the $4^{\text {th }}, 5^{\text {th }}$ and $6^{\text {th }}$ column (data of Model 3 , 4 and 5) of Table 3, expenditure decentralization has a profound impact on decisionmaking of local governments to develop high-polluting industries. For all the 69 key cities, the expenditure decentralization was positive at the statistical level of $1 \%$. It indicates that along with the improvement of expenditure decentralization, the regional industrial structure pollution level also increases. Expenditure decentralization can help to improve the fiscar self-governng power of local governments. In order to ease their financial pressure and maximize their own interests, local governments tend to use their existing capitals to develop 1ocal economy, instead of investing money to improve their local environment. Meanwhile, the current government achievement assessment system puts too much focus on increasing GDP. Therefore, expenditure decentralization would encourage local governments to vigorously develop quickly-yielding and high-profiting industries, and even sacrifice environment to GDP growth, thereby leading to an unhealthy in dustrial structure.

Moreover, as can be seen from Table 3, the regional per capita GDP and the regional industral structure pollution level have a positive correlation, which passes the test of significance. Thus it can be seen that with the economic development, the overall level of China's regional industrial structure pollution has been rising. Data in Table 4 shows that the industrial structure pollution level in key Chinese has been aggravated at an increasingly high rate. Key Chinese cities are line with the prediction of the Environmental Kuznets Curve, but are basically at the decline stage on the left side of the U-shaped curved, so they will go through a long period of development before their environments hit bottom and rebound.

Model 1, 2, 4 and 5 prove that the population density and the regional industrial structure pollution level were significantly and negatively correlated with each other at the level of $1 \%$, which is consistent with the prediction that regions with a greater population density generally have a more rational industrial structure distribution and 
more fully developed tertiary industry. China's population is mainly concentrated in the eastern region. Because of the great population density in the eastern region, high demands are made on its environmental quality. However, the non-eastern region with a sparse population is more likely to develop agriculture, industry and other high-polluting industries.

Regression coefficients of the research intensity as a variable are significantly positive in all models. It indicates that along with the improvement of research and development investment, the regional industrial structure pollution level is rising, which is not difficult to understand. The object of this research is the overall industrial structure instead of a particular industry or region. However, increases in research and development investment would bring different degrees of improvement, according to different development stages and different types of resource allocation. High-polluting industries have greater contribution to outputs in the whole industrial structure, so high-polluting industries can get a greater bonus in the process of increasing the research and development investment. This conclusion is in line with the change trend of sample cities' industrial structure pollution level shown in Table 4. Industrial structure pollution of key Chinese cities is being aggravated in an accelerated rate.

Regression coefficients of the manufacturing degree are positive from Model 1 to Model 6, and most of them pass the significance test at 10. It indicates that an increase in the proportion of the secondary industry can signifjeantly improve the industrial structure pollution level, which conforms to the common sense that a higher manufacturing degree would bring more serious environmental pollution. When China enters a certain stage in its industrialization process, it should make corresponding adjustments and corrections, have an urgent need to change its development pattern, actively adjust its industrial structure, improve its economic growth efficiency, and pursue a new industrialization road of sustainable development o ensure good economic returns, low resource consumption and little environmental pollution.

In Model 1,2,4 and 5, symbols of foreign direct investment dependence are significantly negative, indicating that the introduction of foreign direct investment does not significantly improve the industrial structure pollution level and make China into an "environmental pollution hell", but may promote to improve the environmental quality in China. Along with the economic development, local governments, especially in the eastern region, have begun to attach great importance to the foreign investment quality while actively introducing foreign investment, instead of blindly lowering environmental standards for foreign-funded enterprises. Moreover, technical equipment and advanced management ideas introduced through foreign direct investment have played a positive role in improving the environmental quality of China. However, symbols of foreign direct investment dependence in Model 4 and 6 are negative. This is probably because noneastern cities are under-developed. Therefore, economic growth is a top-priority task for non-eastern cities, so they are more inclined to introduce industrial projects which bring large investment but set aside environmental consequences, thereby causing environmental degradation.

Table 4. 2001-2011 Sample Cities' Changes in the Industrial Structure Pollution Level

\begin{tabular}{cccc}
\hline Year & National & Eastern & Non-eastern \\
\hline 2001 & 0.3115 & 0.3184 & 0.3036 \\
2002 & 0.2832 & 0.2858 & 0.2803 \\
2003 & 0.4819 & 0.4647 & 0.5013 \\
2004 & 0.3817 & 0.3802 & 0.3836 \\
2005 & 0.3586 & 0.3641 & 0.3528 \\
2006 & 0.3881 & 0.3878 & 0.3885 \\
\hline
\end{tabular}




\begin{tabular}{llll}
\hline 2007 & 0.3852 & 0.3845 & 0.3860 \\
2008 & 0.3995 & 0.3964 & 0.4032 \\
2009 & 0.4032 & 0.4027 & 0.4037 \\
2010 & 0.4314 & 0.4305 & 0.4325 \\
2011 & 0.4400 & 0.4345 & 0.4468 \\
\hline
\end{tabular}

As can be seen from Table 4, from 2001 to 2011, fiscal decentralization had caused increasingly serious industrial structure pollution in key Chinese cities as samples of this research. Along with the economic development in China, the industrial structure pollution level in China has been rising in an accelerated rate. The industrial structure pollution level has been rising slowly in eastern key cities, but rising rapidly in noneastern cities, mainly because of the advanced economy in the eastern region. According to the Kuznets theory, the eastern region is close to the left bottom of the U Kuznets curve, with a relatively slow structural change. Moreover, this also illustrates that the fiscal decentralization system cannot solve industrial structure pollution in key Chinese cities, so China should build a more perfect system.

\section{Conclusions}

Dynamic research was made of panel data about 69 key cities from 2001 to 2011 , to draw the following conclusions.

On the one hand, the current fiscal decentralization system in China is not conducive to the eco-friendly development of the Chinese industriab structure. In particular, expenditure decentralization has a significantly positive effect on the rise of the industrial structure pollution level of sampling cities Expenditare decentralization is an important variable to study the continuously rising industriâl pollution level of sampling cities. At present, Chinese local governments face low income decentralization but high expenditure decentralization and bear great pressures from the mismatching between the office authority and expenditure responsibility. With great economic decision-making powers, local governments are more inclined to invest in projects which can produce desired incomes quickly Therefore, local governments have to choose high-polluting and high-consuming industries, or even lower industrial environmental regulative standards to attract businesses and invesment for economic construction. This shows that decentralization is inefficient for improving the environmental quality. Autonomy empower to local governments through decentralization has not brought a high-quality living environment to local residents. In the decentralization system, governments' behavioral motivation plays a key role in determining how to improve and protect the environment. Therefore, the motivation mechanism for local governments requires further improvement, to include environmental protection and management into the government performance evaluation system of local officials, change single-dimensional economic performance evaluation indexes into multi-dimensional and comprehensive social and economicevaluation indexes, and incorporate personal interests of local officials and publicinterests into the assessment system. Otherwise, if environmental improvement is stil considered to be a spontaneous process occurring with economic development, environmental pollution problems will become more serious.

On the other hand, along with the rise of the regional per capita GDP, the regional industrial structure pollution level in China has been rising at an accelerated rate. It is insufficient to purely rely on existing regional environmental regulations and industrial development to solve environmental problems of China. According to research results of this paper, the method of developing science and technology and increase research and development investment is not effective for achieving the desired result of lowering the overall industrial structure pollution level in China. Foreign direct investment has helped to lower the industrial structure pollution level in the eastern region. Drawing lessons 
from this, the middle and eastern region should pay great attention to the selection of foreign direct investment types, to ease regional pollution. China has a vast territory. Different regions in China greatly vary in the population density, economic development level, openness to the outside world, environmental quality requirements and other aspects. In the design of government incentive mechanisms, attention should be paid to regional characteristics of different regions. Moreover, differentiated and specific adjustments should be made of existing government regulations, to avoid rigid uniformity between different regions, in order to achieve better incentive compatibility.

\section{Acknowledgement}

The authors acknowledge support from National Nature Science of China (NSFC, 41471112), Humanities and Social Sciences Fund, Ministry of Education, PRC. (12YJA790064), and Fundamental Research Funds for the Central Universities, (292015155).

\section{References}

[1] Oates E.W. Fiscal federalism. Harcourt Brace Jovanovich. (1972)
[2] WindmeijerF. A finite sample correction for the variance of linear efficient two-step GMM estimators, Journal of econometrics, vol. 126, no. 1, (2005), pp. 25-51

[3] Lin, J., \& Liu, Z. Fiscal decentralization and economi grow th in China, Economic Development and Cultural Change, vol. 49, no. 1, (2000), pp. 1-21.

[4] Zhang, T., \& Zou, H. Fiscal decentralization, publiespending, and economic growth in China. Journal of Public Economics, vol. 67, no. 2, (1998), pp. 221 240.

[5] Blanchard, O., \& Shleifer, A. Federalism with and without political centralization: China vs. Russia in transitional economics: How much progress? MF Staff Papers vol. 48, (2001), pp. 711-179.

[6] ] Maskin, E., Qian, Y., \& Xu, C. Incentives, scale economies, and organization forms. Review of Economic Studies, vol. 67, (2000), pp. 359-378.

[7] Qian, Y., \& Roland, G. Federalism and the soft budget constraint. American Economic Review, vol. 88, no. 5, (1998), pp. 1143-1162

[8] Qian, Y., \& Xu, C. Why Chinas economic reforms differ: The M-form hierarchy and entry/expansion of the non-state sector. The Economics of Transition, vol.1, (1993), pp. 135-170.

[9] Li, H., \& Zhou, L.. Political turnover and economic performance: The incentive role of personnel control in China. Journa of Public Ecônomics, vol. 89, no. 9-10 , (2005), pp. 1743-1762.

[10] Shih, V., Adolph Q \& Liu, M. Getting ahead in the communist party: Explaining the advancement of central committee members in China. The American Political Science Review, vol. 106, no. 1, (2012), pp. 166-187.

[11] Oates E.W..Searching for Ceviathan: An Empirical Study. The American Economic Review, vol. 75, (1985), pp.748-757.1

[12] Cai, F., Du, Y. \&Wang. M. The Political Economy of Emission in China: Will a Low Carbon Growth Be Incentive Compatible in Next Decade and Beyond? Economic Research Journal, no. 6 , (2008), pp. 4-36.

[13] Lin, X., Li, Q. \&Guo, Y. Theoretical and Empirical Analysis of China's Fiscal Decentralization and Environmental Pollution. Economic Survey, no. 5 , (2013), pp. 122-127.

[14] Qu, X. Comprehensive Measure on China's Industrial Environmental Pollution-An Empirical Analysis of Topsis. Industrial Economics Research, no. 4 , (2014), pp. 51-59.

[15] Sun W., Luo D. Zheng, S. \&Wan, G.. Environmental Assessment,Local Official Promotion and

Environmental Management_Empirical Evidence from 86 Main Cities of China ( $2004-2009)$.

ournal of Tsinghua University(Philosophy and Social Sciences), no. 4 , (2014), pp. 49-61. 


\section{Authors}

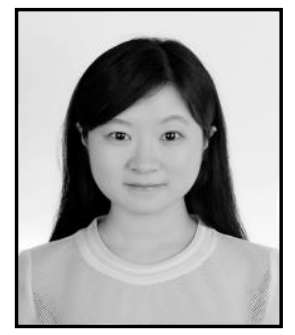

Wang Lanrui, She received her Bachelor degree in Economics from China University of Geosciences (Beijing) in Beijing, China. She is currently a graduate student in school of Humanities and Economic Management of China University of Geosciences (Beijing). Her research interest is mainly in the area of Regional Economic, Resource Economics and Public Administration. She has published several research papers in scholarly journals in the above research areas.

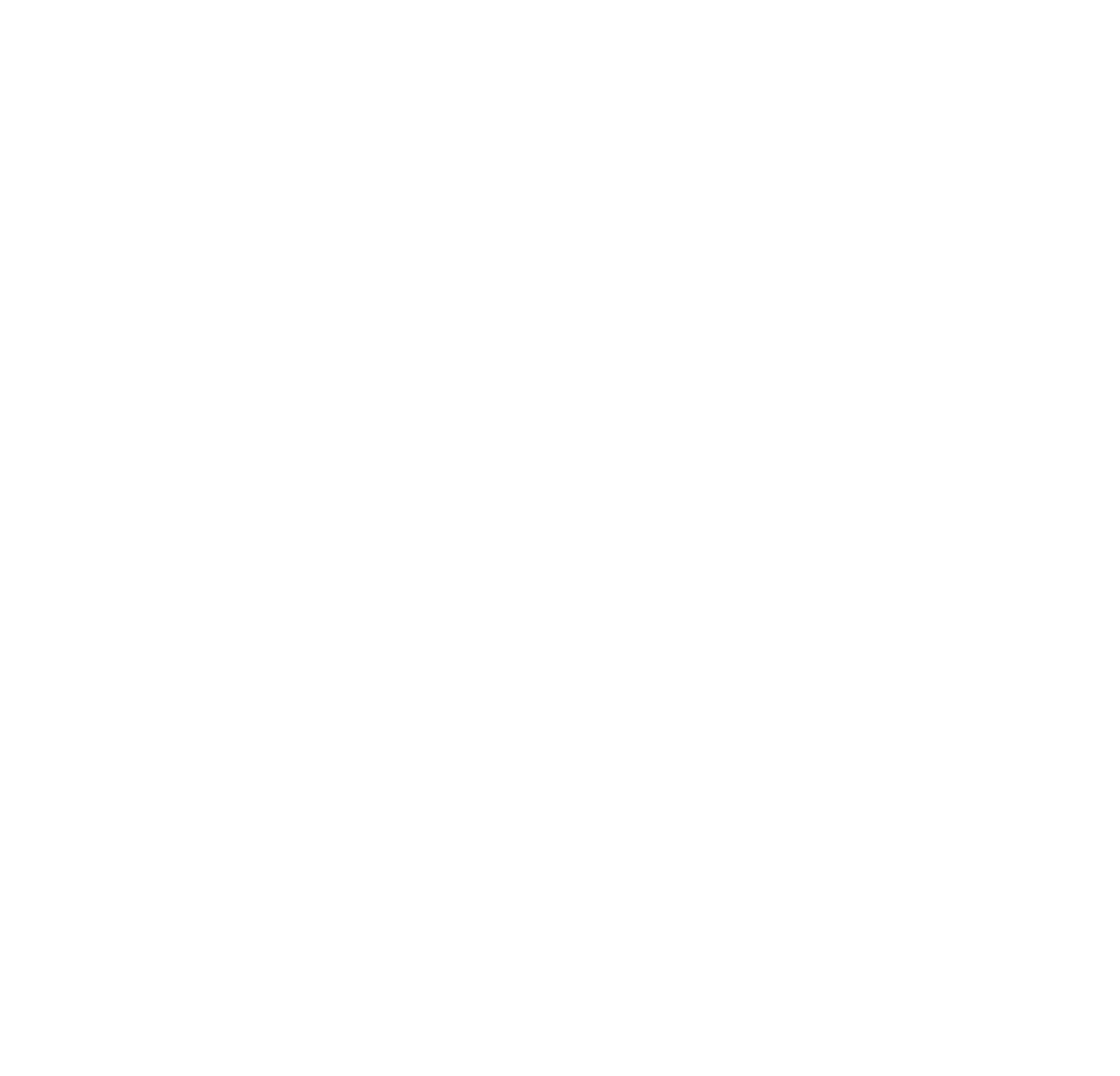

